\title{
Efficient sweet pepper transformation mediated by the BABY BOOM transcription factor
}

\author{
Iris Heidmann $\cdot$ Brenda de Lange $\cdot$ Joep Lambalk • \\ Gerco C. Angenent $\cdot$ Kim Boutilier
}

Received: 23 November 2010/Revised: 18 January 2011/Accepted: 18 January 2011/Published online: 9 February 2011

(C) The Author(s) 2011. This article is published with open access at Springerlink.com

\begin{abstract}
Pepper (Capsicum L.) is a nutritionally and economically important crop that is cultivated throughout the world as a vegetable, condiment, and food additive. Genetic transformation using Agrobacterium tumefaciens (agrobacterium) is a powerful biotechnology tool that could be used in pepper to develop community-based functional genomics resources and to introduce important agronomic traits. However, pepper is considered to be highly recalcitrant for agrobacterium-mediated transformation, and current transformation protocols are either inefficient, cumbersome or highly genotype dependent. The main bottleneck in pepper transformation is the inability to generate cells that are competent for both regeneration and transformation. Here, we report that ectopic expression of the Brassica napus BABY BOOM AP2/ERF transcription factor overcomes this bottleneck and can be used to efficiently regenerate transgenic plants from otherwise recalcitrant sweet pepper (C. аппиит) varieties. Transient activation of BABY BOOM in the progeny plants induced prolific cell regeneration and was used to produce a large number of somatic embryos that
\end{abstract}

Communicated by L. Jouanin.

Electronic supplementary material The online version of this article (doi:10.1007/s00299-011-1018-x) contains supplementary material, which is available to authorized users.

I. Heidmann · B. de Lange · J. Lambalk

Enza Zaden Research and Development B.V, P.O. Box 7,

1600 AA Enkhuizen, The Netherlands

G. C. Angenent · K. Boutilier $(\varangle)$

Plant Research International, Wageningen University

and Research Centre, P.O. Box 619, 6700 AP Wageningen,

The Netherlands

e-mail: kim.boutilier@wur.nl could be converted readily to seedlings. The data highlight the utility of combining biotechnology and classical plant tissue culture approaches to develop an efficient transformation and regeneration system for a highly recalcitrant vegetable crop.

Keywords Sweet pepper (Capsicum anпиит) . Transformation · Agrobacterium · BABY BOOM · Somatic embryogenesis $\cdot$ Regeneration

$\begin{array}{ll}\text { Abbreviations } \\ \text { TDZ } & \text { Thidiazuron } \\ \text { BBM } & \text { BABY BOOM } \\ \text { CCM } & \text { Co-cultivation medium } \\ \text { EM } & \text { Elongation medium } \\ \text { GR } & \text { Rat glucocorticoid receptor ligand binding domain } \\ \text { GUS } & \beta \text {-Glucuronidase } \\ \text { MS } & \text { Murashige and Skoog medium } \\ \text { PRM } & \text { Pre-rooting medium } \\ \text { RM } & \text { Rooting medium } \\ \text { SE } & \text { Somatic embryo } \\ \text { SLS } & \text { Shoot-like structures }\end{array}$

Introduction

The genus Solanaceae comprises some of the most economically important vegetable species, including potato (Solanum tuberosum), tomato (Solanum lycopersicon), eggplant (Solanum melongena), and pepper (Capsicum spp.). More than 40 species belong to the genus Capsicum. Five pepper species, $C$. annuum, $C$. frutescens, $C$. baccatum, C. chinense, and $C$. pubescens, are valuable crops plants that 
are cultivated and consumed throughout the world, with C. annиum being the most widely cultivated species. Pepper is second only to tomato in terms of vegetable production in developed countries, and its breeding and production, as with other major crops, is constantly challenged by numerous pests, diseases, and abiotic stresses (Djian-Caporalino et al. 2007). Trait development in the genus Capsicum is hampered by interspecific crossing barriers, as well as by the general lack of an efficient regeneration system, which is a prerequisite for the introduction of new traits by genetic transformation. The major bottlenecks in Capsicum regeneration are the general low frequency of shoot formation and the development of malformed shoot buds and shoots (variously referred to in the literature as rosette shoots, leafy shoots or blind leaves) that fail to elongate, most likely due to the absence of a shoot apical meristem (Dabauza and Pena 2003; Engler et al. 1993; Kothari et al. 2010; Liu et al. 1990; Mihálka et al. 2003; Wolf et al. 2001). In general, the chili (hot) pepper types are much more responsive for in vitro regeneration than the sweet pepper types (Dabauza and Pena 2001; Engler et al. 1993; Khan et al. 2006; Lopez-Puc et al. 2006; Ochoa-Alejo and Ramirez-Malagon 2001; SolísRamos et al. 2010; Zapata-Castillo et al. 2007) although a strong genotype dependency has been observed in both.

Agrobacterium tumefaciens (agrobacterium)-mediated transformation of $C$. апnиum has been described in the literature, but in most reports only a few transgenic lines were obtained, and/or the transformation efficiency and heritability of the transgene were not reported (Dabauza and Pena 2003; Manoharan et al. 1998; Mihálka et al. 2003; Shivegowda et al. 2002; Zhu et al. 1996). Reproducible agrobacterium-mediated transformation is currently limited to a few responsive chili pepper genotypes (Ko et al. 2007; Lee et al. 2004) and one sweet-mini pepper genotype (Engler et al. 1993; Harpster et al. 2002). The difficulties associated with pepper transformation have been attributed to its low regeneration capacity, and the poor overlap between the tissues that are competent for agrobacterium infection and those that are competent for regeneration (Wolf et al. 2001). This is a general phenomenon that has been observed in plants that are recalcitrant for transformation (Potrykus 1991). A system that supports transformation and regeneration of the same tissues could therefore provide the basis for an efficient pepper transformation protocol.

A number of genes encoding transcription factors, cell cycle proteins, and components of hormone biosynthesis and signaling pathways have been shown to enhance plant regeneration responses when mutated or ectopically expressed (Banno et al. 2001; Catterou et al. 2002; Lotan et al. 1998; Riou-Khamlichi et al. 1999; Zuo et al. 2002). One of these genes, BABY BOOM (BBM), encodes an AP2/ ERF transcription factor that induces regeneration under culture conditions that normally do not support regeneration in wild-type plants. Ectopic expression of Brassica napus BBM (BnBBM) genes in B. napus and the related crucifer arabidopsis (Arabidopsis thaliana) induces spontaneous somatic embryogenesis and organogenesis from seedlings grown on hormone-free basal medium (Boutilier et al. 2002). In tobacco, ectopic $B B M$ expression is sufficient to induce adventitious shoot and root regeneration on basal medium, but exogenous cytokinin is required for somatic embryo (SE) formation (Srinivasan et al. 2007). Ectopic BBM expression has also been used to generate transgenic Chinese white poplar (Populus tomentosa Carr.) plants (Deng et al. 2009). Poplar callus transformed with a B. rapa BBM gene developed SEs that could be converted into plantlets, while untransformed callus failed to regenerate. The system was combined with heat shock-inducible FRT/FLP-mediated excision of the transgene to produce marker-free lines.

Transformation strategies based on standard tissue culture approaches have not led to efficient pepper transformation protocols. We therefore examined whether the positive influence of $B B M$ expression on regeneration that is observed in other plant species could be transferred to pepper. Here, we describe the efficient regeneration of large numbers of fertile transgenic plants of two C. аппиит sweet pepper varieties by combining a classical tissue culture approach with transient activation of a BnBBM protein.

\section{Materials and methods}

Explant pre-culture

Surface sterilized seeds of the F1 hybrids Fiesta, Ferrari, and Spirit (Enza Zaden, The Netherlands) were sown on full strength MS medium (Murashige and Skoog 1962) with $2 \%(\mathrm{w} / \mathrm{v})$ sucrose (pH 5.8, MS20) solidified with $0.8 \%$ (w/v) Microagar. Ten-day-old petiole-free cotyledons were cut twice, transverse to the mid-rib, to generate three explants, which were then pre-cultured on solid $(0.7 \%$ Microagar) co-cultivation medium (CCM) supplemented with $40 \mathrm{mg} / \mathrm{l}$ acetosyringone (Acros Organics) for 1-2 days under dim light conditions (1,500 lux) at $23^{\circ} \mathrm{C}$. CCM is a modified R medium (Sibi et al. 1979) supplemented with $1.6 \%(\mathrm{w} / \mathrm{v})$ glucose, $2 \mathrm{mg} / \mathrm{l}$ zeatin riboside and $0.1 \mathrm{mg} / \mathrm{l}$ indole-3-acetic acid to promote shoot regeneration.

Agrobacterium and vectors

Agrobacterium strain GV3101 carrying the pMP90 Ti plasmid was used in all experiments. Agrobacterium containing the $35 S:: B n B B M: G R$ (Srinivasan et al. 2007) and 
$35 S:: G U S$ binary vectors were grown with the appropriate antibiotics in $100 \mathrm{ml} \mathrm{YEB}$ medium at $28^{\circ} \mathrm{C}$. Prior to transformation the agrobacterium suspension was diluted to $\mathrm{OD}_{660}$ 0.3-0.4 with liquid CCM supplemented with freshly prepared $40 \mathrm{mg} / \mathrm{l}$ acetosyringone.

\section{Transformation and regeneration}

The diluted agrobacterium culture was added to the precultured cotyledon explants and incubated at room temperature for 30-60 min. Explants were blotted dry and further co-cultured on CCM supplemented with $40 \mathrm{mg} / \mathrm{l}$ acetosyringone for 2-3 days under dim light conditions $(1,500 \mathrm{lux})$ at $23^{\circ} \mathrm{C}$ before transfer to selection medium consisting of CCM supplemented with $1 \mathrm{mg} / \mathrm{l}$ thidiazuron (TDZ), $100 \mathrm{mg} / \mathrm{l}$ kanamycin sulfate and $500 \mathrm{mg} / \mathrm{l}$ cefotaxime. Explants were transferred to full light conditions (3,000 lux) on a $16 \mathrm{~h} / 8 \mathrm{~h}$ day/night cycle at $23^{\circ} \mathrm{C}$ for 2 months. The medium was refreshed after 4 weeks. Explants with emerging shoots or shoot-like structures (SLS) were transferred for 4 weeks to elongation medium (EM) consisting of MS macro- and microsalts (Murashige and Skoog 1962), B5 vitamins (Gamborg et al. 1968), 1.6\% (w/v) glucose, $1 \mathrm{mg} / \mathrm{l}$ inositol, $20 \mathrm{mg} / \mathrm{l}$ adenine sulfate, $200 \mathrm{mg} / 1$ casein hydrolysate, $10 \mathrm{mg} / 1$ gibberellic acid 3 , $4 \mathrm{mg} / \mathrm{l}$ benzylaminopurine and $30 \mu \mathrm{M}$ silverthiosulfate. Elongated shoots were transferred to pre-rooting medium (PRM), comprising MS20 medium supplemented with $30 \mathrm{mg} / \mathrm{l}$ glutathione, $60 \mathrm{mg} / \mathrm{l}$ kanamycin sulfate, and $300 \mathrm{mg} / \mathrm{l}$ cefotaxime. The shoots were transferred after 1 month to rooting medium (RM; Rugini 1984) supplemented with $2 \%$ (w/v) sucrose, $50 \mathrm{mg} / \mathrm{l} \mathrm{kanamycin}$. Rooted shoots were transferred into the greenhouse for seed set. All media used in experiments involving the $35 S:: B n B B M$ : $G R$ construct were supplemented with $10 \mu \mathrm{M}$ dexamethasone (DEX; Sigma) up to the point where shoots were transferred to EM, after which DEX-free media was used. Except where noted, all tissue culture chemicals were supplied by Duchefa Biochemicals (Haarlem, The Netherlands).

\section{$\beta$-Glucuronidase (GUS) staining}

Histochemical GUS staining (Jefferson 1987) of $35 S:: G U S$ explants was performed after 3 weeks on selection medium.

Evaluation of stable transgenic lines of $35 S:: B n B B M: G R$

Surface sterilized seeds were sown on MS20 medium supplemented with either $10 \mu \mathrm{M}$ DEX, $1 \mathrm{mg} / \mathrm{TDZ}$, or
$10 \mu \mathrm{M}$ DEX plus $1 \mathrm{mg} / \mathrm{l} \mathrm{TDZ}$. The response of the seedlings was evaluated 24 days after sowing.

Root, hypocotyl, and cotyledon explants from 10-dayold seedlings and leaf explants from 4-week-old plantlets were obtained from donor material grown on MS20 without any supplements. Explants were placed on MS20 or MS20 supplemented with $10 \mu \mathrm{M}$ DEX, either alone or in combination with $1 \mathrm{mg} / \mathrm{l} \mathrm{TDZ}$, benzylaminopurine or zeatin riboside. The response of the explants was evaluated after 2 weeks. Conversion of SEs into plantlets was assessed by placing embryos onto RM. Conversion into plantlets was evaluated 4 weeks after transfer to RM.

\section{Results}

\section{BABY BOOM-mediated regeneration}

We examined the utility of a $B n B B M$ gene as a tool to enhance regeneration during agrobacterium-mediated transformation of $C$. annuum sweet, blocky pepper types. Ectopic BBM expression induces pleiotropic phenotypes such as adventitious growth and sterility that are likely to interfere with the regeneration process and subsequent growth of transgenic plants (Boutilier et al. 2002). To avoid generating plants with detrimental phenotypes, we expressed a fusion between the BnBBM protein and the ligand binding domain of the rat glucocorticoid receptor (BBM:GR), which sequesters the BBM transcription factor in the cytoplasm in the absence of glucocorticoid steroid, e.g., DEX (Passarinho et al. 2008; Srinivasan et al. 2007). Explants were co-cultivated with agrobacterium carrying either the 35S::BnBBM:GR construct or a control $35 S:: G U S$ construct carrying the scorable GUS marker. Both constructs confer kanamycin resistance via the nptII selection marker. Explants were co-cultivated with agrobacterium on CCM and then transferred to CCM medium containing kanamycin until shoots appeared, at which point the shoots were transferred to EM. Elongated shoots were then transferred to PRM and subsequently to RM when rooting did not occur already on PRM. Approximately 5,600 explants from two cultivars were used in the transformation experiments with the $35 S:: G U S$ plasmid, and approximately 6,400 explants from three cultivars in the transformation experiments with the $35 S:: B n B B M: G R$ plasmid (Table 1).

Cotyledon explants that were co-cultivated with agrobacterium containing the $35 S:: G U S$ construct behaved as previously described for poorly regenerating or nontransformable genotypes (Lee et al. 2004; Liu et al. 1990). The explants increased in size about twofold during the first 3 weeks on selection medium. Small calli became 
Table 1 Regeneration response and transformation efficiency of sweet pepper varieties

\begin{tabular}{|c|c|c|c|c|c|c|}
\hline Construct/cultivar & $\begin{array}{l}\text { No. of } \\
\text { explants }\end{array}$ & $\begin{array}{l}\text { No. of } \\
\text { experiments }\end{array}$ & $\begin{array}{l}\text { Explants with SLS } \\
\text { (\% of total explants used })\end{array}$ & $\begin{array}{l}\text { Explants with } \\
\text { elongated shoots }\end{array}$ & $\begin{array}{l}\text { No. transgenic } \\
\text { shoots }^{\mathrm{a}}\end{array}$ & $\begin{array}{l}\text { Transformation } \\
\text { efficiency }^{b}\end{array}$ \\
\hline \multicolumn{7}{|l|}{$35 S:: G U S$} \\
\hline Fiesta & 5,150 & 24 & $64(1.2)$ & 0 & & \\
\hline Spirit & 475 & 5 & $0(0)$ & 0 & & \\
\hline Total & 5,625 & 29 & 64 & 0 & 0 & 0 \\
\hline \multicolumn{7}{|l|}{$35 S:: B n B B M: G R$} \\
\hline Fiesta & 4,448 & 25 & $798(17.9)$ & 26 & 78 & 0.6 \\
\hline Ferrari & 805 & 6 & $29(3.6)$ & 9 & 20 & 1.1 \\
\hline Spirit & 1,179 & 7 & $67(5.7)$ & 0 & & 0 \\
\hline Total & 6,432 & 38 & 894 & 35 & 98 & \\
\hline
\end{tabular}

${ }^{\text {a }}$ Individual explants produce multiple shoots

b Transformation efficiency $=$ (no. of explants with transgenic shoots/total no. of explants $) \times 100 \%$

visible at the cut edge of the explants during the following 2-4 weeks, accompanied by a few dense rosetteforming SLS (Fig. 1a, b). SLS transferred to EM failed to elongate and therefore did not root when transferred to rooting medium (RM). In vitro grafting of the SLS onto a wild-type rootstock did not promote further shoot development or elongation, suggesting that the SLS lacked a functional apical meristem. In a separate experiment, histochemical staining of 3-week-old explants $(n=225)$ that formed both SLS and callus showed that $6 \%$ of the explants exhibited GUS activity and that the GUS activity was restricted to the developing callus (Fig. 1c). This observation supports the hypothesis of Wolf et al. (2001) that under these conditions, pepper cells that are susceptible for agrobacterium transfection lack regeneration capacity and vice versa.

In contrast to the control experiments with the $35 S:: G U S$ construct, co-cultivation of sweet pepper cotyledon explants with agrobacterium carrying the $35 S:: B n B B M: G R$ construct allowed us to generate numerous transgenic
Fig. 1 Regeneration response of sweet pepper explants. Response of sweet pepper 'Fiesta' explants to cocultivation with agrobacterium carrying either the $35 S$ :GUS construct $(\mathbf{a}-\mathbf{c})$ or the $35 S:: B n B B M: G R$ construct $(\mathbf{d}-\mathbf{f})$. a Callus formation (arrow) and shoot-like structures (SLS; asterisk) after 3 weeks of culture; b leaf-like structures developing at the wounded edge of a cotyledon after 4 weeks of culture; c explant with callus (arrow) and SLS (asterisk) histochemically stained for GUS activity; d SLS, 4 weeks after treatment; e somatic embryo formation (arrows) on a newly emerged leaf, after 6 weeks of culture; $\mathbf{f}$ elongating SLS (asterisk) after 4 weeks on elongation medium
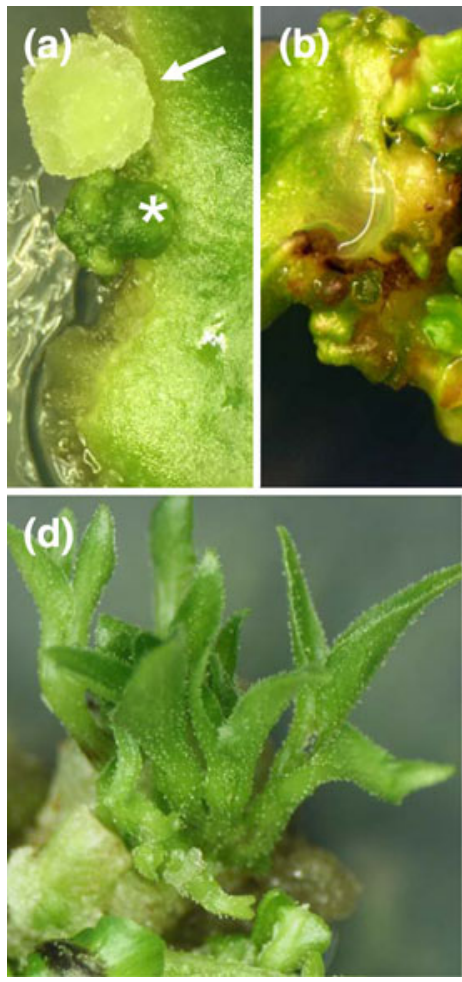
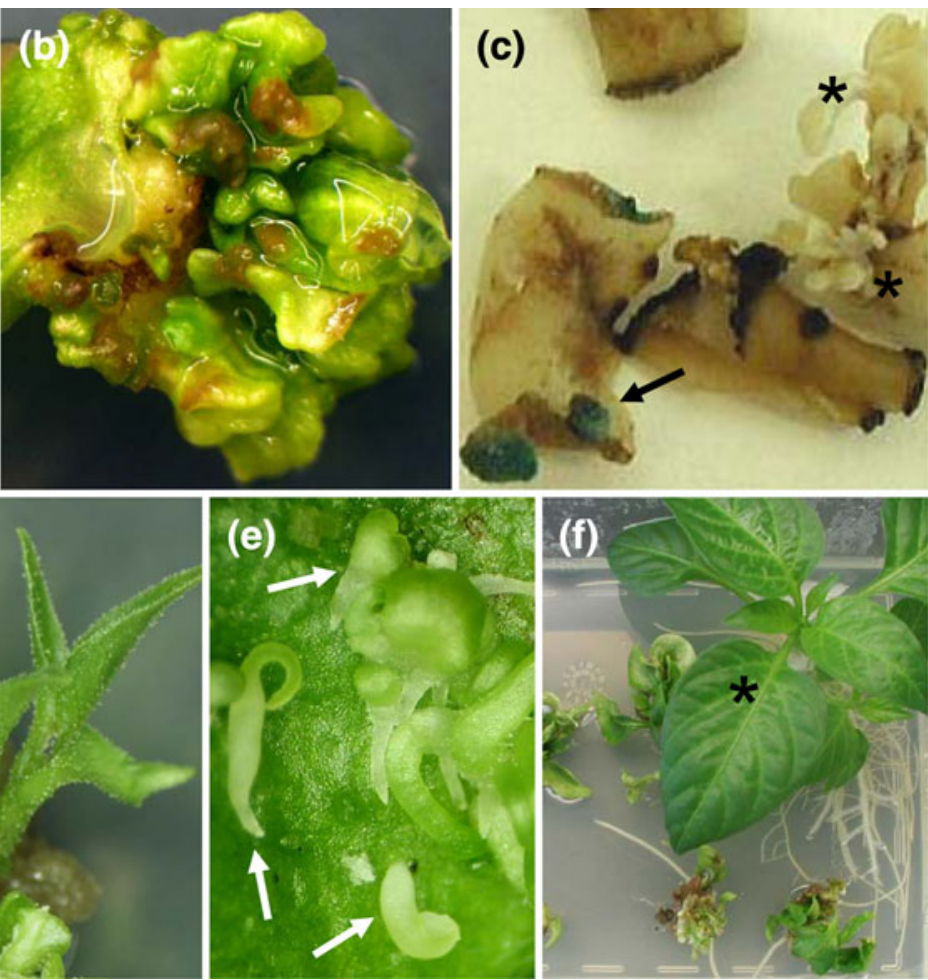
Table 2 Workflow for 35S::BnBBM:GR-mediated sweet pepper transformation

\begin{tabular}{|c|c|c|}
\hline Step & $\begin{array}{l}\text { Days } \\
(n)\end{array}$ & Medium \\
\hline Growth of donor material & 10 & MS20 \\
\hline Explant pre-culture & $1-2$ & $\mathrm{CCM}+\mathrm{ZR}+\mathrm{IAA}$ \\
\hline Co-cultivation of explants & $3-4$ & $\mathrm{CCM}+\mathrm{ZR}+\mathrm{IAA}+\mathrm{ACS}$ \\
\hline $\begin{array}{l}\text { Shoot regeneration on } \\
\text { selective medium }\end{array}$ & $2 \times 30$ & $\mathrm{CCM}+\mathrm{TDZ}+\mathrm{DEX}$ \\
\hline Shoot elongation & 30 & EM \\
\hline $\begin{array}{l}\text { Pre-rooting of elongated } \\
\text { shoots }\end{array}$ & 30 & PRM \\
\hline Rooting of elongated shoots & 14 & RM \\
\hline Total & 150 & \\
\hline
\end{tabular}

$C C M$ co-cultivation medium, MS20 Murashige and Skoog (1962) with $2 \%$ (w/v) sucrose, $Z R$ zeatin riboside, $I A A$ indole-3-acetic acid, $A C S$ acetosyringone, TDZ thidiazuron, $D E X$ dexamethasone, $E M$ elongation medium, $P R M$ pre-rooting medium, $R M$ rooting medium

shoots that stably transmitted the transgene to the next generation. The transformation experiments with the $35 S:: B n B B M: G R$ plasmid were carried out as described above, except that $10 \mu \mathrm{M}$ DEX was included in the selection medium to localize the BBM:GR protein to the nucleus. Explants co-cultivated with the $35 S:: B n B B M: G R$ agrobacterium behaved essentially the same as in the $35 S:: G U S$ experiments during the first 7 weeks of culture, except that they produced more SLS in each experiment compared to the $35 S:: G U S$ control (Table 1). Unlike the control experiments with $35 S:: G U S$, the SLS that formed after co-cultivation with the $35 S:: B B M: G R$ agrobacterium elongated and proliferated within 4 weeks after transfer to EM (Fig. 1d). SEs developed occasionally on the leaves of elongated shoots and/or SLS that remained in contact with the medium (Fig. 1e), and in turn produced elongated shoots. Plantlet formation from elongated shoots was enhanced after transfer to PRM (Fig. 1f). Shoots that did not root on PRM formed roots within 2 weeks after transfer to RM. An overview of the workflow for our sweet pepper transformation protocol is shown in Table 2.

In total, 98 rooted shoots regenerated from 35 independent SLS were transferred to the greenhouse. PCR on T0 plants and germination of T1 seed on kanamycin-containing medium suggested that all 98 plants were transgenic (data not shown and Supplementary Table 1). A more detailed PCR analysis of $65 \mathrm{~T} 1$ lines derived from 31 SLS (Supplementary Fig. 1) showed that the 35S::BBM fragment (located close to the right T-DNA border) could be amplified in all 65 lines, while the nos::nptII fragment (located close to the left border) could only be amplified in 62/65 lines (Supplementary Fig. 1). The three lines lacking the nos::nptII fragment showed kanamycin resistance, suggesting that the selection marker was truncated during T-DNA integration but is still functional.

Regeneration and transformation efficiency

The regeneration response of the three tested varieties was greatly enhanced in the experiments with the $35 S:: B n B B M: G R$ plasmid (Table 1) although genotypic differences were observed among the varieties with respect to the different steps in the regeneration protocol. In all cases, co-cultivation with the $35 S:: B n B B M: G R$ plasmid was able to relieve one or more bottlenecks in the regeneration/transformation procedure for each of the varieties tested. Transgenic plantlets were generated for two of the three varieties, whereas no transgenics were obtained from any variety in the control experiments. Numerous elongated shoots could be produced from a single SLS. However, as multiple shoots may arise from a single transformation event, we only used a single elongated shoot per SLS to calculate the transformation efficiency (Table 1). Based on this criterion, we obtained average transformation efficiencies of 0.6 and $1.1 \%$ for the two varieties although the transformation efficiency can be much higher in individual experiments (up to $3.8 \%$, data not shown). Different segregation patterns were often observed among the progeny of the multiple shoots derived from a given SLS (Supplementary Table 1), suggesting that multiple independent transgenic plants can be regenerated from a single explant. TAIL-PCR was performed on $65 \mathrm{~T} 1$ lines derived from 31 SLS to determine whether multiple lines from a single SLS correspond to clonal or independent transgenic events. The TAIL-PCRs were not successful for every set of SLS, but we were able to identify five SLS in which the corresponding lines with more than one TAIL PCR fragment. An example is shown in Supplementary Fig. 2. Together, the data suggest that the actual transformation efficiency is higher than calculated above.

Stable $35 S:: B n B B M: G R$ transformants are highly regenerative

Two single locus, homozygous $35 S:: B n B B M$ :GR lines were selected for further phenotypic analysis. Seeds were sown on either MS20, MS20 supplemented with either DEX or TDZ or MS20 supplemented with both DEX and TDZ. Seedlings of the two $35 S:: B n B B M: G R$ lines were indistinguishable from the wild type when grown on MS20 (Fig. 2a). 35S::BnBBM:GR seedlings grown on DEX-containing medium were severely delayed in their initial growth as compared to wild-type plants growing on the same medium. Seedlings from one of the two lines germinated, but failed to develop further. Seedlings of both 
Fig. 2 Regeneration response of stable $35 S:: B B M: G R$ sweet pepper lines. a-d 24-day-old seedlings germinated on medium with the indicated supplements; e-h feather-cut cotyledons of 10-day-old seedlings incubated for 14 days on medium with the indicated supplements. Shoot-like structures are indicated by an arrow; $\mathbf{i}-\mathbf{l}$ feather-cut leaves of 4-week-old plants incubated for 14 days on medium with the indicated supplements; m 35S::BBM:GR somatic embryos; $\mathbf{n}$ immature wild-type zygotic embryo; o somatic embryo formation on wild-type zygotic embryos. MS20 Murashige and Skoog medium with $2 \%$ (w/v) sucrose, $T D Z$ thidiazuron, $D E X$ dexamethasone

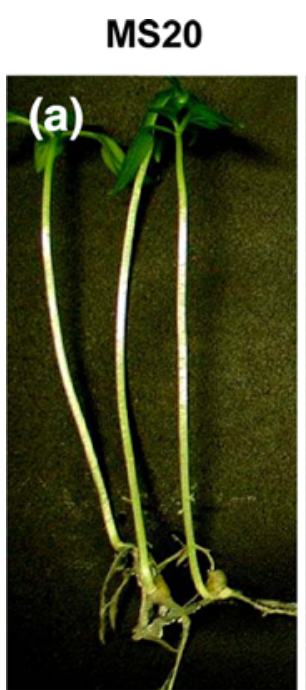

DEX

TDZ TDZ+DEX
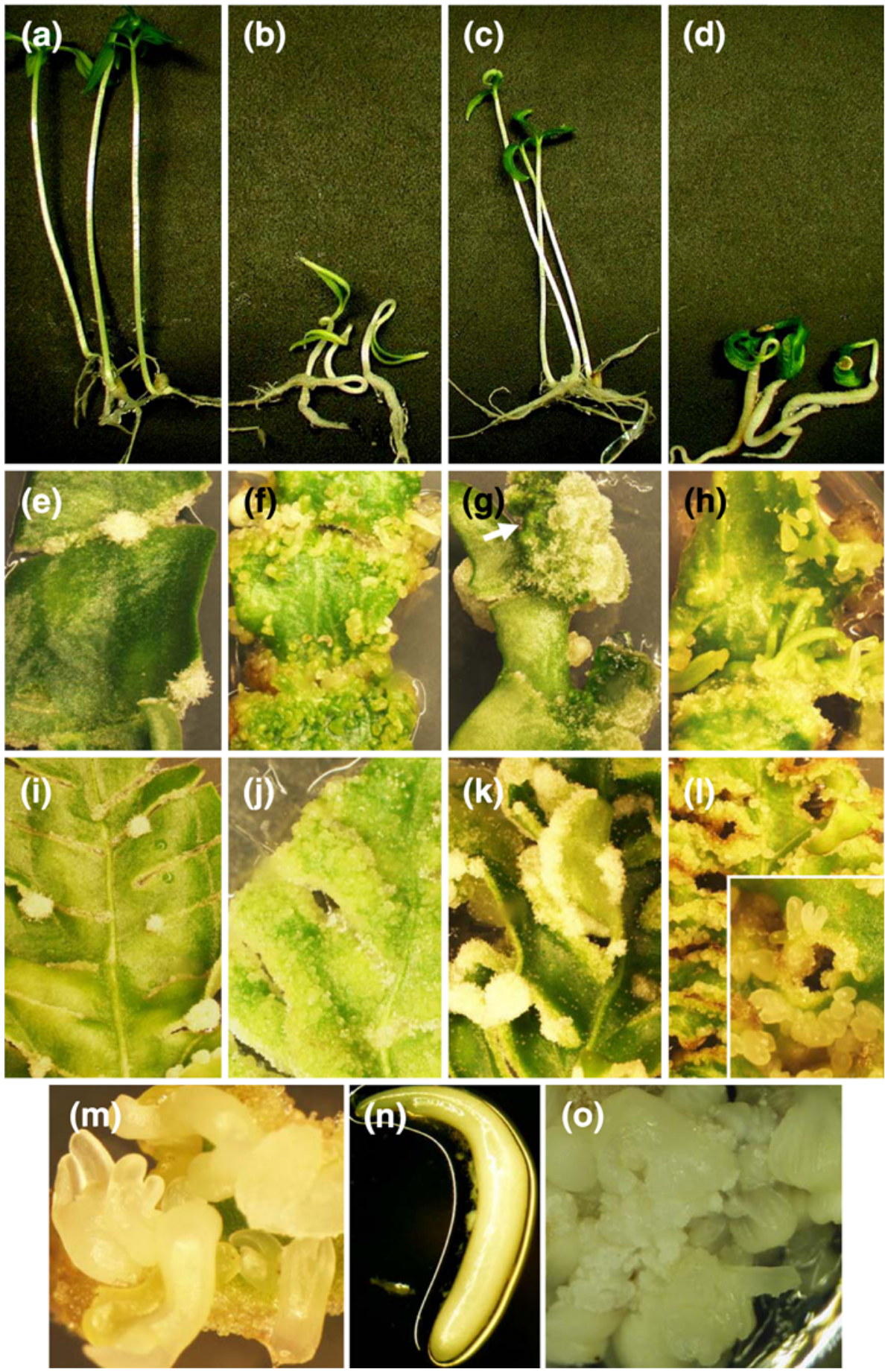

lines showed a thickened root, a pronounced apical hook (Fig. 2b) and were agravitropic. The cotyledons that remained in contact with the medium eventually swelled and formed irregular protruberances lacking a defined structure. Wild-type and 35S::BnBBM:GR seedlings plated on TDZ-containing medium developed as on the control MS20 medium (Fig. 2c). Wild-type and 35S::BnBBM:GR seedlings growing on medium supplemented with both DEX and TDZ showed a combination of the phenotypes observed in the presence of the individual compounds (Fig. 2d). In addition, cotyledons of $35 S:: B n B B M: G R$ seedlings that remained in contact with the medium eventually developed into a callus mass and produced a few SEs (data not shown). 
The ability of $35 S:: B n B B M: G R$ explants to form SEs prompted us to assess the regenerative capacity of different organs. Segments of roots and hypocotyls and feather-cut cotyledons from 10-day-old seedlings, and feather-cut leaves from 4-week-old homozygous $35 S:: B n B B M: G R$ plants were placed onto MS20 or MS20 supplemented with TDZ, DEX or both TDZ and DEX. Root and hypocotyls segments formed callus but did not regenerate under any of the conditions tested (data not shown). Cotyledons and leaves cultured on MS20 formed white callus at the wounded edges of the explant (Fig. 2e, i). TDZ stimulated white callus production in cotyledons and leaves, and also induced SLS formation at the wounded edges of cotyledons (Fig. 2g, k). Culturing cotyledons and leaves on medium with DEX (Fig. 2f, j) or DEX and TDZ (Fig. 2h, l) induced prolific SE formation. SE induction was greatly diminished when uncut leaves and cotyledons were used as explants (data not shown). Quantitative differences in SE production were not observed when TDZ was replaced by the cytokinins benzylaminopurine and zeatin riboside (data not shown). SE induction was mainly observed on the surface of the explant adjacent to the cut edge, and SEs appeared to develop directly from the underlying tissue, rather than indirectly through an intermediate callus phase. SEs formed on DEX-containing medium generally developed to the globular stage (Fig. 2f, j), while SEs growing on medium containing TDZ (or other cytokinins) and DEX progressed further to the heart-shaped stage and beyond, in which the cotyledons are visible (Fig. 2h, 1). SEs from 35S::BBM:GR explants induced on TDZ (or other cytokinins) and DEX have a clear bipolar structure (Fig. 2m), and are more similar to wild-type zygotic embryos (Fig. 2n) than to standard SEs derived from immature wild-type zygotic embryos (Fig. 2o). $35 S:: B B M: G R$ SEs could be converted into plantlets by plating them on RM. While individual cytokinins did not affect SE production quantitatively, they did influence the ability of SEs to convert into plantlets. The highest conversion rate $(50 \%)$ was obtained with embryos that were induced in the presence of benzylaminopurine (Supplementary Table 2).

\section{Discussion}

Pepper is a major crop that is grown world-wide and whose production is threatened by various biotic and abiotic stresses. Resistances can often be found in wild relatives, but there are often strong breeding incompatibilities between Capsicum species that are not easy to circumvent (Jae et al. 2006; Onus and Pickersgill 2004). Traits from incompatible wild relatives could be introduced into cultivated peppers via genetic transformation; however, peppers, especially the sweet genotypes, are highly recalcitrant for transformation.

Here, we describe a reliable and efficient transformation protocol for sweet pepper genotypes that takes advantage of the enhanced regeneration response conferred by the BBM AP2/ERF transcription factor. The protocol is straightforward in that additional measures such as grafting SLS onto a rootstock (Mihálka et al. 2003), a long phase of shoot elongation ("normalization") (Engler et al. 1993) or the addition of auxin to enhance rooting (Engler et al. 1993; Khan et al. 2006) were not required. Direct comparison of our sweet pepper transformation efficiencies with published protocols is difficult as in practice there are no routine, reliable and reproducible protocols that are applicable to more than one genotype. The comparison is further complicated by the lack of information on the transformation efficiency (Harpster et al. 2002; Zhu et al. 1996) or the heritability of the transgene (Dabauza and Pena 2003; Engler et al. 1993; Manoharan et al. 1998; Mihálka et al. 2003; Shivegowda et al. 2002). Our transformation efficiencies of 0.6 and $1 \%$ obtained with two recalcitrant sweet pepper genotypes are higher on average than the $0.03-0.6 \%$ reported for the most responsive C. апnиит. chili pepper genotypes (Ko et al. 2007; Lee et al. 2004; Manoharan et al. 1998).

This and previous studies (Wolf et al. 2001) suggest that the few regenerating structures that are obtained in standard pepper transformation protocols are not susceptible for agrobacterium-mediated transformation. The mechanism by which the BBM protein closes the gap in competencies for transformation and regeneration in pepper is not clear. BBM might exert a positive effect on the transformation efficiency by creating a cellular environment that is both susceptible to transformation and regeneration, or by increasing the total number of regenerating cells (SLS), thereby increasing the probability that both processes coincide in one cell. $35 S:: B B M: G R$ explants not only produce a higher number of SLS than control explants; they also elongate to produce shoots at a higher frequency. Again, the underlying mechanism is not clear. Both $35 S:: G U S$ and $35 S:: B B M: G R$ explants initially produce morphologically similar SLS that grow in dense rosettes with no clear boundaries between them, suggesting a nonfunctional or missing SAM. Somewhere during the regeneration of BBM-SLS, a functional SAM and vascular bundles are formed that allow the shoots to elongate and develop into a normal plant. The ability of BBM to induce direct regeneration, i.e., without an intervening callus phase, may promote improved shoot polarity and differentiation.

Efficient in vitro regeneration systems based on somatic embryogenesis can facilitate the classical breeding process by providing large amounts of clonal material for 
propagation, as well as explants for transformation. SE production from immature zygotic embryos on solid medium has been reported in $C$. апnиum (chili and sweet pepper types) and C. chinense although the induction frequencies are low (maximum 8 SE/explant) (Binzel et al. 1996; Harini and Lakshmi Sita 1993; Steinitz et al. 2003), and the SEs can exhibit a high frequency of morphological defects that affects their conversion into seedlings (Steinitz et al. 2003). Solís-Ramos et al. (2009) used inducible expression of the arabidopsis WUSCHEL (WUS) homeobox transcription factor (Zuo et al. 2002) to enhance SE formation in $C$. chinense $\mathrm{L}$. A small number of globular structures could be induced to form on primary stem explants transformed with the inducible WUS construct butthe embryos failed to develop further and eventually died. In contrast, stable $35 S:: B B M: G R$ transgenics exhibited an extremely high regeneration capacity, producing hundreds to thousands of well-formed embryos per explant that could be converted at a high frequency into seedlings.

A number of strategies can be used to implement a BBM-based transformation technology. For example, a second gene of interest can be co-transformed along with the $35 S:: B B M: G R$ construct or stable, highly regenerative $35 S:: B B M: G R$ transformants could be used as explants for the introduction of a second gene of interest. In both examples, the positive effect of the BBM protein on the regeneration process can serve as a selectable marker during (co-)transformation of a second gene of interest, which can itself be selected in the classical way (e.g., using antibiotic- or herbicide resistance) or via PCR. For some purposes it may be desirable to avoid stable integration of the 35S::BBM:GR transgene. This could be circumvented by transient expression techniques (Vergunst et al. 2000) or by segregation of the $35 S:: B B M: G R$ transgene in progeny lines.

The sweet pepper transformation system described here opens up possibilities for the introduction of new disease and abiotic stress resistances, as well as for important reproductive and architecture traits. In addition to these practical applications, this transformation system provides opportunities for building up fundamental research tools that can be used to understand gene function in Capsicum spp.

Open Access This article is distributed under the terms of the Creative Commons Attribution Noncommercial License which permits any noncommercial use, distribution, and reproduction in any medium, provided the original author(s) and source are credited.

\section{References}

Banno H, Ikeda Y, Niu QW, Chua NH (2001) Overexpression of Arabidopsis ESR1 induces initiation of shoot regeneration. Plant Cell 13:2609-2618
Binzel ML, Sankhla N, Joshi S, Sankhla D (1996) Induction of direct somatic embryogenesis and plant regeneration in pepper (Capsicum annuum L.). Plant Cell Rep 15:536-540

Boutilier K, Offringa R, Sharma VK, Kieft H, Ouellet T, Zhang L, Hattori J, Liu CM, van Lammeren AA, Miki BL, Custers JB, van Lookeren Campagne MM (2002) Ectopic expression of BABY BOOM triggers a conversion from vegetative to embryonic growth. Plant Cell 14:1737-1749

Catterou M, Dubois F, Smets R, Vaniet S, Kichey T, Van Onckelen H, Sangwan-Norreel BS, Sangwan RS (2002) hoc: an Arabidopsis mutant overproducing cytokinins and expressing high in vitro organogenic capacity. Plant J 30:273-287

Dabauza M, Pena L (2001) High efficiency organogenesis in sweet pepper (Capsicum annuum L.) tissues from different seedling explants. Plant Growth Regul 33:221-229

Dabauza M, Pena L (2003) Response of sweet pepper (Capsicum anпиит L.) genotypes to Agrobacterium tumefaciens as a means of selecting proper vectors for genetic transformation. J Hortic Sci Biotechnol 78:65-72

Deng W, Luo K, Li Z, Yang Y (2009) A novel method for induction of plant regeneration via somatic embryogenesis. Plant Sci 177:43-48

Djian-Caporalino C, Lefebvre V, Sage-Daubèze AM, Palloix A (2007) Capsicum. In: Singh RJ (ed) Genetic resources, chromosome engineering, and crop improvement. CRC Press, Boca Raton, pp 185-243

Engler DE, Guri AZ, Lauritis JA, Schloemer LMP (1993) Genetically transformed pepper plants and methods for their production. International patent application WO93/09665

Gamborg OL, Miller RA, Ojima K (1968) Nutrient requirement of suspension cultures of soybean root cells. Exp Cell Res 50:151-158

Harini I, Lakshmi Sita G (1993) Direct somatic embryogenesis and plant regeneration from immature embryos of chilli (Capsicum апnиит L.). Plant Sci 89:107-112

Harpster MH, Brummell DA, Dunsmuir P (2002) Suppression of a ripening-related endo-1,4- $\beta$-glucanase in transgenic pepper fruit does not prevent depolymerization of cell wall polysaccharides during ripening. Plant Mol Biol 50:345-355

Jae BY, Dong CY, Jae WD, Hyo GP (2006) Overcoming two postfertilization genetic barriers in interspecific hybridization between Capsicum annuum and C. baccatum for introgression of anthracnose resistance. Breed Sci 56:31-38

Jefferson R (1987) Assaying chimeric genes in plants: the GUS gene fusion system. Plant Mol Biol Rep 5:387-405

Khan H, Siddique I, Anis M (2006) Thidiazuron induced somatic embryogenesis and plant regeneration in Capsicum annuum. Biol Plant 50:789-792

Ko MK, Soh H, Kim K-M, Kim YS, Im K (2007) Stable production of transgenic pepper plants mediated by Agrobacterium tumefaciens. HortScience 42:1425-1430

Kothari SL, Joshi A, Kachhwaha S, Ochoa-Alejo N (2010) Chilli peppers-a review on tissue culture and transgenesis. Biotechnol Adv 28:35-48

Lee YH, Kim HS, Kim JY, Jung M, Park YS, Lee JS, Choi SH, Her NH, Lee JH, Hyung NI, Lee CH, Yang SG, Harn CH (2004) A new selection method for pepper transformation: callus-mediated shoot formation. Plant Cell Rep 23:50-58

Liu W, Parrott WA, Hildebrand DF, Collins GB, Williams EG (1990) Agrobacterium induced gall formation in bell pepper (Capsicum annиuт L.) and formation of shoot-like structures expressing introduced genes. Plant Cell Rep 9:360-364

Lopez-Puc G, Canto-Flick A, Barredo-Pool F, Zapata-Castillo P, Montalvo-Peniche MDC, Barahona-Perez F, Santana-Buzzy N, Iglesias-Andreu L (2006) Direct somatic embryogenesis: A highly efficient protocol for in vitro regeneration of 
habanero pepper (Capsicum chinense Jacq.). HortScience 41:1645-1650

Lotan T, Ohto M-a, Yee KM, West MAL, Lo R, Kwong RW, Yamagishi K, Fischer RL, Goldberg RB, Harada JJ (1998) Arabidopsis LEAFY COTYLEDON1 is sufficient to induce embryo development in vegetative cells. Cell 93:1195-1205

Manoharan M, Vidya CSS, Sita GL (1998) Agrobacterium-mediated genetic transformation in hot chilli (Capsicum annиum L. var. Pusa jwala). Plant Sci 131:77-83

Mihálka V, Balázs E, Nagy I (2003) Binary transformation systems based on 'shooter' mutants of Agrobacterium tumefaciens: a simple, efficient and universal gene transfer technology that permits marker gene elimination. Plant Cell Rep 21:778-784

Murashige T, Skoog F (1962) A revised medium for rapid growth and bio assays with tobacco tissue cultures. Physiol Plant 15:473-497

Ochoa-Alejo N, Ramirez-Malagon R (2001) In vitro chili pepper biotechnology. In Vitro Cell Dev Biol Plant 37:701-729

Onus AN, Pickersgill B (2004) Unilateral incompatibility in Capsicum (Solanaceae): occurrence and taxonomic distribution. Ann Bot 94:289-295

Passarinho P, Ketelaar T, Xing M, van Arkel J, Maliepaard C, Hendriks M, Joosen R, Lammers M, Herdies L, den Boer B, van der Geest L, Boutilier K (2008) BABY BOOM target genes provide diverse entry points into cell proliferation and cell growth pathways. Plant Mol Biol 68:225-237

Potrykus I (1991) Gene transfer to plants: assessment of published approaches and results. Annu Rev Plant Physiol Plant Mol Biol 42:205-225

Riou-Khamlichi C, Huntley R, Jacqmard A, Murray JAH (1999) Cytokinin activation of Arabidopsis cell division through a D-type cyclin. Science 283:1541-1544

Rugini E (1984) In vitro propagation of some olive (Olea europaea sativa L.) cultivars with different root-ability, and medium development using analytical data from developing shoots and embryos. Sci Hortic 24:123-134

Shivegowda ST, Mythili JB, Anand L, Saiprasad GVS, Gowda R, Gowda TKS (2002) In vitro regeneration and transformation in chilli pepper (Capsicum annuum L.). J Hortic Sci Biotechnol 77:629-634
Sibi M, Dumas de Vaulx R, Chambonnet D (1979) Obtention de plantes haploides par androgenese in vitro chez le piment (Capsicum annuum L.) Ann Amelior Plantes 29:583-606

Solís-Ramos L, González-Estrada T, Nahuath-Dzib S, Zapata-Rodriguez L, Castaño E (2009) Overexpression of WUSCHEL in $C$. chinense causes ectopic morphogenesis. Plant Cell Tissue Organ Cult 96:279-287

Solís-Ramos L, Nahuath-Dzib S, Andrade-Torres A, Barredo-Pool F, González-Estrada T, de la Serna E (2010) Indirect somatic embryogenesis and morphohistological analysis in Capsicum chinense. Biologia 65:504-511

Srinivasan C, Liu Z, Heidmann I, Supena E, Fukuoka H, Joosen R, Lambalk J, Angenent G, Scorza R, Custers J, Boutilier K (2007) Heterologous expression of the BABY BOOM AP2/ERF transcription factor enhances the regeneration capacity of tobacco (Nicotiana tabacum L.). Planta 225:341-351

Steinitz B, Küsek M, Tabib Y, Paran I, Zelcer A (2003) Pepper (Capsicum annuum L.) regenerants obtained by direct somatic embryogenesis fail to develop a shoot. In Vitro Cell Dev Biol Plant 39:296-303

Vergunst AC, Schrammeijer B, Den Dulk-Ras A, De Vlaam CMT, Regensburg-Tuink TJG, Hooykaas PJJ (2000) VirB/D4-dependent protein translocation from Agrobacterium into plant cells. Science 290:979-982

Wolf D, Matzevitch T, Steinitz B, Zelcer A (2001) Why is it difficult to obtain transgenic pepper plants? Acta Hortic 560:229-233

Zapata-Castillo PY, Flick A-C, Lopez-Puc G, Solis-Ruiz A, Barahona-Perez F, Santana-Buzzy N, Iglesias-Andreu L (2007) Somatic embryogenesis in habanero Pepper (C. chinense Jacq.) from cell suspensions. HortScience 42:329-333

Zhu Y-X, Wen-Jun O-Y, Yi-Feng Z, Zhang-Liang C (1996) Transgenic sweet pepper plants from Agrobacterium mediated transformation. Plant Cell Rep 16:71-75

Zuo J, Niu Q-W, Frugis G, Chua N-H (2002) The WUSCHEL gene promotes vegetative-to-embryonic transition in Arabidopsis. Plant J 30:349-359 